\title{
Low-carbon benefit analysis on DG penetration distribution system
}

\author{
Shaoyun GE, Li XU, Hong LIU (ه), \\ Jian FANG
}

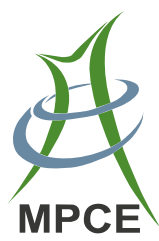

\begin{abstract}
In response to the severe energy and environmental issues, $\mathrm{CO}_{2}$ emission reduction and low-carbon development are inevitable. China has become the biggest $\mathrm{CO}_{2}$ emitter in the world since 2006. As a major $\mathrm{CO}_{2}$ emission source in China, the power industry is facing greater pressure for carbon emission abatement. By applying various low-carbon power technologies and mechanisms, the potential for $\mathrm{CO}_{2}$ emission reduction in power systems is considerable. This paper proposes a pseudo-sequential Monte Carlo simulation method for the low-carbon benefit evaluation of distribution system including distributed wind turbines, solar array and battery energy storage systems. The hourly sequential models and state variation models for wind turbines, solar array and battery are established. The non-power components are sequentially sampled and the components of the wind turbine, the solar array and the battery are non-sequentially sampled. The failure modes and effect analysis (FMEA) procedure for the system are discussed and the heuristic load shedding approach is used, then the low-carbon benefit evaluation procedure is illustrated. Based on this, the system state transition sampling method for calculating the loss of expected energy index with high DG penetration is proposed. The state transition models for non-active elements and DGs are established. The validity of the
\end{abstract}

CrossCheck date: 12 December 2014

Received: 29 September 2014/Accepted: 5 January 2015/Published online: 22 January 2015

(C) The Author(s) 2015. This article is published with open access at Springerlink.com

S. GE, L. XU, H. LIU, Key Laboratory of Smart Grid,

Tianjin University, Tianjin 300072, China

$(\bowtie)$ e-mail: liuhong@tju.edu.cn

L. XU

e-mail: xuligodfather@gmail.com

J. FANG, Electric Power Research Institute, Guangzhou Power

Supply Company, Guangzhou 510000, China proposed method is demonstrated by a study case. The method can be used for the low-carbon benefit analysis on DG penetration distribution networks.

Keywords Low-carbon, Distribution generation penetration, Distribution system, Monte Carlo simulation method

\section{Introduction}

Climate change and energy crises have become two important challenges for the sustainable development of human society since entering the new millennium. Excessive use of non-renewable fossil fuels is a main cause for concern [1-6]. In China, the proportion of thermal power installed capacity has exceeded $70 \%$, and $\mathrm{CO}_{2}$ emission of thermal power generation accounts for over $95 \%$ of the total emission of power industry. Hence, implementation of carbon emission reduction in China's power industry is critical and fundamental to coping with the challenges of global warming. China has embarked on a low-carbon and resource efficient development pathway, with the focuses on developing clean energy and addressing environmental problems [7-9]. As a significant part in energy supply, the distribution system is vital for the development of clean distribution energies, such as distributed wind turbines and solar array [10-14]. The Chinese Government decided to build smart grids and develop domestic emission trading system to facilitate the deployment of green energies and to reduce $\mathrm{CO}_{2}$ emissions [15-19].

As an effective complement to centralized power generation, distributed generation (DG) technologies are becoming mature. With flexible operational mode and environment-friendly features, more and more distributed generations are integrated into the distribution network, 
which brings benefit on the carbon reduction of distribution system [20]. As two basic methods of loss of expected energy (LOEE) for the distribution system with DG, the studies of analytical method [21-29] and Monte Carlo method [30-36] have made some progress. These studies indicate that the adoption of DG is actually equals to increasing the number and capacity of the backup of distribution system, thus improving the carbon reduction of the distribution system.

In Section 2, the boundary conditions of the study are confined. In Section 3, the DGs mathematical modeling are introduced, and the Monte Carlo simulation methods designed for energy without the high penetration case are proposed in detail. In Section 4, a study case is used to exemplify the methods mentioned above. Finally, the conclusion is drawn in Section 5.

\section{System configuration}

Alternative architectures are possible for the electrical interconnection of DG components, including the possibility for DC interconnection of PV stations to the battery inverters, and all components are connected to the AC distribution network, due to its superior flexibility. In any case, this is not a central issue, from the point of view of energy calculations. To achieve high DG penetration levels, the system must be capable of operating in "DG-only" mode, i.e., with the upper level energy out of supplied. For this purpose, the BESS inverter should provide frequency and voltage regulation, while additional technical requirements may also exist, including the provision of sufficient short-circuit capacity for proper operation of the network overcurrent protection. For this purpose, additional devices, such as synchronous condensers, may be foreseen, while flywheels may also be used for primary frequency response, to reduce pressure on the BESS system. While such technical issues are fundamental for a real-world system, in the analysis presented in this paper emphasis is placed on the energy transactions between system components on relatively long time scales (hours and beyond), and hence, all dynamic phenomena and associated components have been ignored.

\section{Modeling and simulation}

\subsection{Simulation principles}

Modeling of the system accounts for the energy transactions between the various components, while all electric transients are ignored, so that long-term simulations (e.g., annual) are possible. A one hour simulation time step is used, and scheduling decisions are made at the beginning of each simulation hour.

In low DG penetration situation, the upper level power supply is considered as sufficient to the load, the DG act as a supplement to the system, the system is operated as a distribution system. When in high DG penetration situation, the DG act as a main power source, and the upper level power supply needs not to be sufficient, when the system components are in normal condition, the system is actually operated as a generation system, the reliability assessment is used as energy sufficiency one.

FMEA method is used for simplify the network, it only matters when the high DG penetration system state is in fault, and the system reliability assessment process is the same as in low DG penetration system at this moment and the FMEA method was used the same as be mentioned in the simulation of the low penetration. When the high DG penetration system is in normal state, the system transfers to the generation state, and the generation reliability assessment process does not need to use FMEA method to be simplified. And the FMEA method is just simply mentioned as [37] in low DG penetration section in this paper because it is a mature tool to simplify the network and it is not the core work of this paper.

The low DG integration system reliability assessment uses the pseudo-sequential Monte Carlo simulation method because it only needs to focus on fault incident of the system, and ignore normal state of the system, thus making the assessment simple and efficient. But for the high DG penetration system, the reliability assessment needs to calculate the energy balance of the system at every hour, for tens of thousands of years simulation, the simulation for every component is meaningless and redundancy. So in high DG penetration system, we adopt the system state transition sampling method, the sample object is the system state instead of the state of each component, thus simplifying the simulation work.

\subsection{DG modeling}

Real-time wind speeds are generated in each period of a year with autoregressive moving average model in [38], based on which real-time output of wind turbines is calculated by output curve of wind turbine generation (WTG) [39].

Real-time output of photovoltaic (PV) panels is calculated by real-time solar radiation and output curve [40] like output model of wind turbines.

This paper chooses the lead-acid battery as the battery energy storage system (BESS). A variant of the kinetic battery model (KiBaM) [41] is used to simulate the leadacid BESS. 
Using real time outputs of DG was to coordinate the real time load model to make the simulation closer to the reality situation, the time interval was set as 1 hour because for the Monte Carlo simulation method, the simulation time would be reach tens of thousands of years to obtain the convergence result of reliability, longer time interval would make the result inaccurate, and shorter time interval would not be more accurate, but increase calculation work enormously. Considering the repair time of network equipment is in hours, we use 1 hour interval as DG output interval. And for the real-time wind speed model, we chose the widely used autoregressive moving average model in [38] to obtain the real time wind speeds, the outcome result of autoregressive moving average model for the wind speed is in $1 \mathrm{~h}$ time interval.

\section{$3.3 \mathrm{CO}_{2}$ emission issue}

According to fuel combustion data of coal, a complete combustion of coal equivalent $\mathrm{CO}_{2}$ emission factors was $2.62 \mathrm{~kg} \mathrm{CO} / \mathrm{kg}$. The coal consumption of load center and power generation base were both $310 \mathrm{~kg} /(\mathrm{MWh})$ [7].

\subsection{Simulation of low penetration}

\subsubsection{Sequential sampling for non-source component}

All non-source components used the two-state Markov model, as shown in Fig. 1, and the Monte Carlo Simulation Method for state duration sampling was adopted for its sequential sampling [42, 43].

\subsubsection{Sampling for $D G$}

Without considering the limitation of upper system capacity, only when the non-source components in system are in fault, the outage of DG and BESS can exacerbate the power off risk of the user. Compared with normal state, the fault duration of the non-source components is very short, DG and BESS states can be considered to be unchanged during the fault, so their state can be sampled nonsequentially.

Single wind turbine is still using two-state Markov model in Fig. 1. For wind turbine set consisting of $\mathrm{m}$ wind turbine units, $m$ random number between $[0,1]$ is first generated on behalf of its sample state, $R_{i}>P_{d}$ represents that the unit is working.

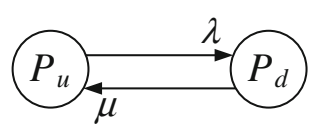

Fig. 1 Two-state Markov model

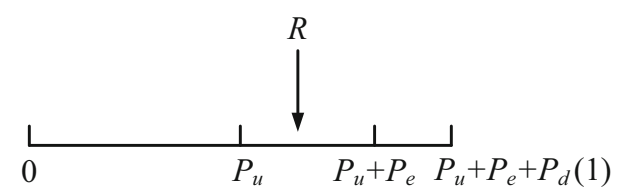

Fig. 2 Sampling process for the three-state element

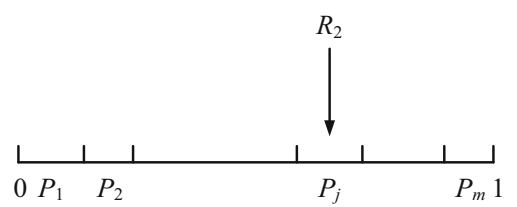

Fig. 3 Explanation of system state transition sampling

PV array consists of a set of photovoltaic panels, to reflect a portion of $\mathrm{PV}$ array fault, on the basis of two-state model, the derating state is added, its probability is $P_{e}$. Sampling process is shown in Fig. 2. Firstly, the probability of all the states is cumulatively placed on number axes between $[0,1]$, the random number $R$ represents the state, that is, PV array. For example, in Fig. 3, the photovoltaic array is in derating state.

The sample of the BESS state consists of two parts: one is sample of the running state, the other is sample of the state of charge (SOC). Sampling methods for the running state is same with PV array, the derating state represents a part of BESS failure. When sampling the SOC, SOC is converted from a random number in accordance with the SOC changing law on integration mode.

\subsubsection{Failure mode and effect analysis (FMEA) process}

FMEA analysis is the basis of LOEE assessment. The DG integration will have an impact on the traditional FMEA process. The FMEA process in [37] is used in this paper.

\subsubsection{Load shedding strategy}

Load shedding determination conditions: at any moment of battery discharge during island, the greatest power of all the battery can be released to be no less than the net exchange power in island:

$\sum_{i=1}^{n} P_{\text {out }, 1}^{i}(t) \eta_{d} \geq P_{\text {ex }}(t) \quad P_{\text {ex }}(t) \geq 0, t \in\left[t_{\text {st }}, t_{\text {end }}\right]$

where $P_{\text {out }, 1}^{i}(t)$ is the maximum power which can be released by the battery pack $i$ during time interval $t ; n$ is the number of battery pack; $P_{e x}(t)=L(t)+S_{l}(t)-D(t)$, in which $L(t)$ is the total load; $D(t)$ is the sum of all DG output; $S_{l}(\mathrm{t})$ is the active power loss within island, to 
simplify the flow calculation, $S_{l}(\mathrm{t})$ can be set at about $5 \%$ of the current load [44].

In order to improve simulation speed, this paper takes the following heuristic load shedding strategies: Firstly, assuming that all load points are not shed, when the case does not meet the following conditions: (1) the smallest load is shed firstly, repeat this process until it satisfies (1). During load shedding process, the dynamic switching was not considered so the shedding state was unchanged during islanding time. When (1) is satisfied, each battery power is released by the proportional ratio of $P_{o u t, 1}^{i}(t)$, and the power is to be absorbed by proportional ratio of $\max \left(P_{i n, 1}^{i}(t),-P_{i n, 2}^{i}(t),-P_{i n, 3}^{i}(t)\right)$. It should be noticed that, for the load points in downstream quarantine segment and downstream active islanding segment, if a load point is shed in both parts of the two island time, the power off frequency is 1 , and the power outage time is the sum of two part.

\subsubsection{Simulation process}

1) Input the network structure, use the method in Section 3.4.3, automatically traversing feeder segments classification of all non-faulty components by computer, establish FMEA table.

2) Set initial analog clock value for 0 , at this time all system components are in normal state. Each non-source system component generates a random number, use the state transition model to generate TTF for each component.

3) Find the component with the smallest TTF (TTFmin), and advance the analog clock to TTFmin. If some components are of the same TTF, randomly select one of them.

4) Generate a new random number and convert it into TTR for this component. At the same time, generate power isolation and recovery time (RT).

5) By using the FMEA table generated in Step 1, check the feeder segments under this component outage. The outage time of the fault segment load point is TTR, the upstream quarantine segment load point outage time is RT, and record the time duration of power outages and the insufficient of power supply.

6) For each upstream active island segment, sample DG state and BESS's SOC at TTFmin, calculate real-time output of DG and load during [TTFmin, TTFmin + RT], use the method in Section 3.4.4 to shed load, record the frequency and duration of load point outage.

7) Similar to Step 6, in [TTFmin, TTFmin + RT], simulate the downstream active island; in [TTFmin + RT, TTFmin + TTR], simulate the downstream big island, and record the frequency and duration of the load point outage.
8) For the faulty component in Step 3, re-generate a random number and convert it into TTFN for a new running time. At the moment, the component's TTF is updated to TTFmin + TTR + TTFN.

9) If the analog clock is less than predetermined simulation time, return to Step 3; otherwise, statistically count the outage frequency, duration and insufficient of each load points, and then calculate the LOEE index.

\subsection{Simulation of high penetration}

\subsubsection{Feature of high penetration system}

High penetration distribution network with DG will have both power generation and distribution properties, socalled as active distribution network, the key of its LOEE assessment, is how to properly combine power generation and distribution properties together. To solve this problem, this paper uses the sequential Monte Carlo sampling method based on the system state transition sampling to conduct the LOEE assessment for distributed network at high DG penetration level, thus it can simultaneously calculate the LOEE index of power generation and distribution.

\subsubsection{System state transition sampling method}

The system state transition sampling method is focused on the state of the whole system rather than that of on component in the system. Assuming that the system is composed of $m$ components consisting of $n$ states. The state space of the system is $G=\left\{S_{1}, S_{2}, \ldots, S_{n}\right\}$. Supposing that the present system state is $S_{k}$ and the state transition rate of each component in the system is $\lambda_{i}(i=1,2, \ldots, m)$. Since the state duration of each component follows an exponential distribution, the duration of the system state $S_{k}$ also follows the exponential distribution. The duration of the system state $S_{k}$ has the probability density function as:

$f(t)=\sum_{i=1}^{m} \lambda_{i} \exp \left(-\sum_{i=1}^{m} \lambda_{i} t\right)$

It can be seen that the state transition rate to the next state from the system state $S_{k}$ is the sum of state transition rate of each component in the system state $S_{k}$.

State transition of any component in the system can lead to a system state. Consequently, the system has $m$ possible states starting from state $S_{k}$. The probability that the system reaches one of these possible states is given as:

$P_{j}=\lambda_{j} / \sum_{i=1}^{m} \lambda_{i}$

where $\lambda_{j}$ is the state transition rate of the $j$ th component. 
It is obviously that:

$\sum_{j=1}^{m} P_{j}=1$

Two uniformly distributed random numbers $R_{1}$ and $R_{2}$ between $[0,1]$ are generated to sample the duration of the system state $S_{k}$ and the system state which will be reached. The duration of the system state $S_{k}$ is given by (5):

$T_{k}=-\ln R_{1} / \sum_{i=1}^{m} \lambda_{i}$

The next system state can be determined by the sampling shown in Fig. 3. The probabilities of $m$ possible future states are successively placed in the interval $[0,1]$. If $R_{2}$ falls into the segment corresponding to $P_{j}$. The transition of the $j$ th component leads system to the next system state.

\subsubsection{Analysis and simulation of generation state}

According to different states of the components in the system, the state space of the distribution system with distributed generation $G$ can be divided into two sub sets $G_{1}$ and $G_{2}$. In the set $G_{1}$, all non-source components are in normal state, in the set $G_{2}$, a non-source element is in fault state.

In the traditional distribution system, when all nonsource components are in normal state, the system load can be supplied without considering the higher level power supply capacity. But the distribution system with DG is a multiple supply network, thus the load in it will be supplied by both DG and the higher level power. Because DG can supply part of the load, the substation capacity will be reduced in order to reduce carbon emission. So it is necessary to consider the impact of the higher level power supply capacity. In this case, whether the total generation of the system including DG can supply all the load needs to be assessed. It is in fact a part of the LOEE evaluation of generation system.

The LOEE of generation system can be evaluated by simple simulation. The LOEE index is determined by superposing the chronological load curve on the generation capacity curve. Assume that the supply from higher level is $P_{S}(t)$, and the DG provides $P_{D G}(t)$ during the $t$ th period. The sum of the real time load and the loss is $P_{L}(t)$ (Assuming that the loss is $5 \%$ of the load to simplify the power flow calculation [45]). It means that the system is suffering power shortage when $P_{s}(t)+P_{D G}(t)<P_{L}(t)$. The LOEE index of generation system is calculated with sequential simulation during all periods. The method will be improved with the consideration of battery charging and discharging strategy. Two dispatch strategies of battery used in the paper are as follows [46].
Load-following strategy: On the load-following strategy, renewable power sources charge the BESS but the generators do not. The BESS is discharged when DG cannot provide enough supply to the load. The generators serve as the backup.

Cycle charge strategy: When DG output is surplus, the BESS is charged by excess power; when DG output is insufficient, if the maximum output of DG and BESS still cannot meet needs of all the loads, the system will firstly supply the remaining load, then to charge the BESS. In addition, to prevent the battery be in a low SOC, once the battery starts charging, it needs to be charged to a specified $K_{\text {SOCset }}$.

Figures 4 and 5 show the simulation process in load following strategy and in cycle charging strategy, respectively. $P_{d}^{i}(t)$ is the maximum output of the $i$ th BESS during the $t$ th period. $P_{c}^{i}(t)$ is the maximum active power that the battery could absorb. Considering the difference of the capacity and SOC between batteries, the exchanging power of each battery is proportional to its $P_{d}^{i}(t)$ or $P_{c}^{i}(t)$. For example, when the DG is charging all the batteries, the $i$ th battery can be obtained:

$P_{e x}^{i}(t)=\left(P_{D G}(t)-P_{L}(t)\right) \times P_{c}^{i}(t) / \sum_{i=1}^{m} P_{c}^{i}(t)$

However, the power that it really absorbs $P_{i n}^{i}(t)$ is $\min \left\{\eta_{c} P_{e x}^{i}(t), P_{c}^{i}(t)\right\} . \eta_{c}$ is charge efficiency.

\subsubsection{Simulation process}

The time sequential Monte Carlo simulation using system state transition sampling evaluates the LOEE of distribution system containing distributed wind energy, solar energy and BESS. The step for simulation is 1 hour. The procedure consists of the following steps:

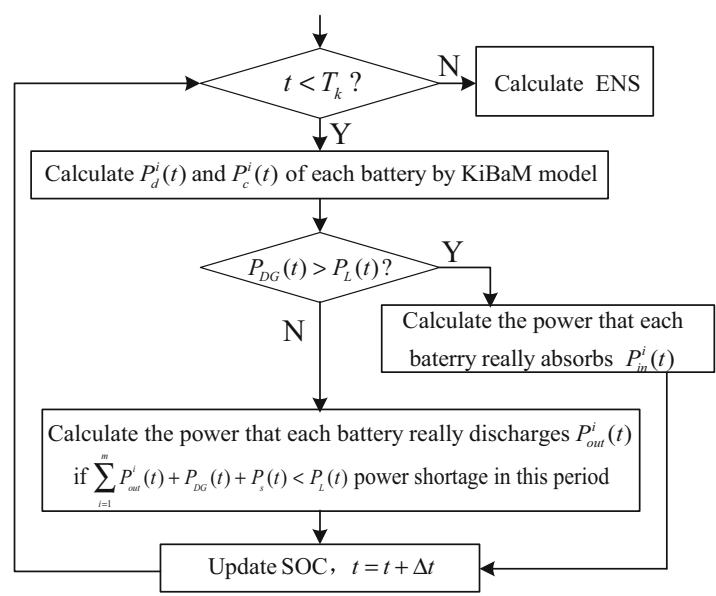

Fig. 4 Simulation process in load-following strategy 


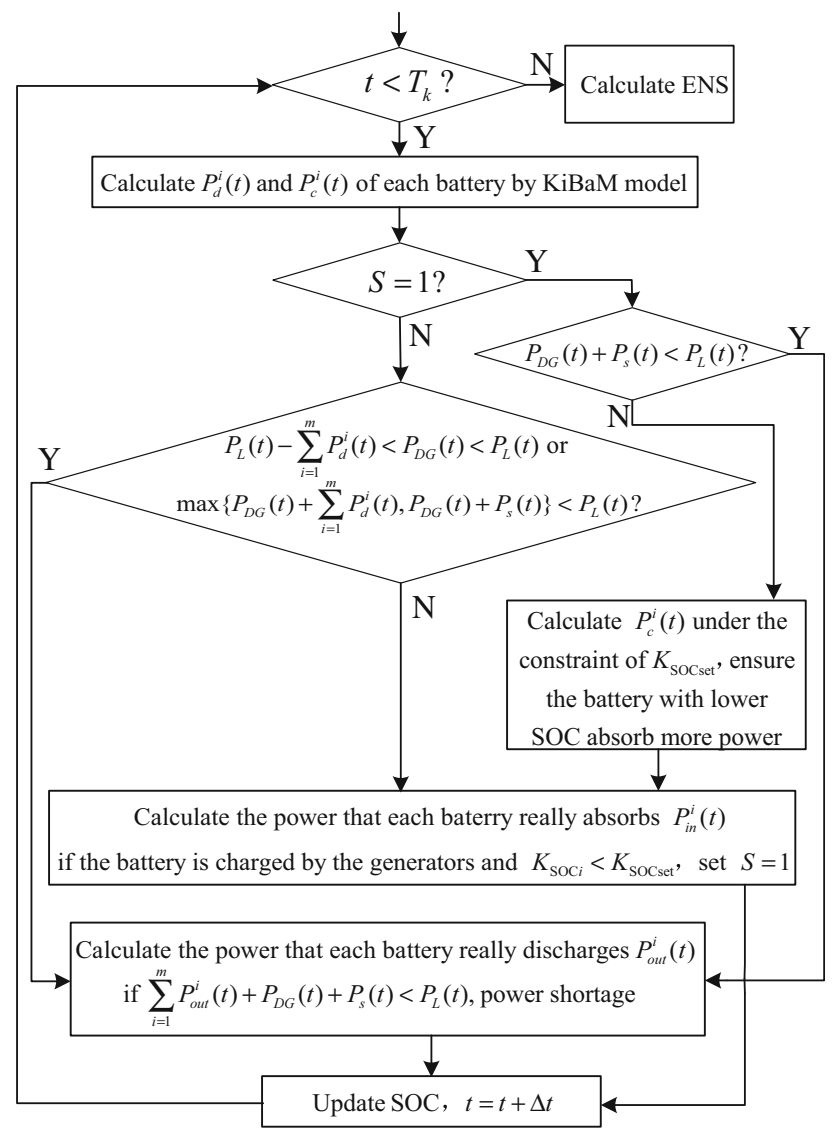

Fig. 5 Simulation process in cycle charging strategy

1) The simulation process starts from the normal system state in which all generating units and transmission components are in the up state at $t_{0}=0$.

2) Calculate the duration of the current system state $T_{k}$ by (4) with the transition rate $\lambda_{i}$ of each component. Get $\lambda_{i}$ of a three-state component by adding its two state transition rates. If the present system state is a state in which at least one non-power component is in fault state, set the transition rate of other components zero.

3 ) If all the non-power components are in the normal state in the current state, call the generation system simulation process, record the energy not supplied $\left(K_{E N S_{k}^{i}}\right)$ during $T_{k}$. If there is a non-power component in fault state, call the distribution system simulation process shown in $E$ and record the indices $\lambda_{k}^{i}, \gamma_{k}^{i}$ and $K_{E N S_{k}^{i}}$.

4) Set $t_{0}=t_{0}+T_{k}$ If the time is shorter than the year limit, sample the next system state by the method in Fig. 1 and go to Step 2. If $t_{0}$ is longer than $N$, stop simulating and calculate the LOEE index (MWh/year):

$K_{L O E E}=\frac{1}{N} \sum_{k=1}^{P} K_{E N S_{k}}$

where $P$ is the simulation times of the generation system state.

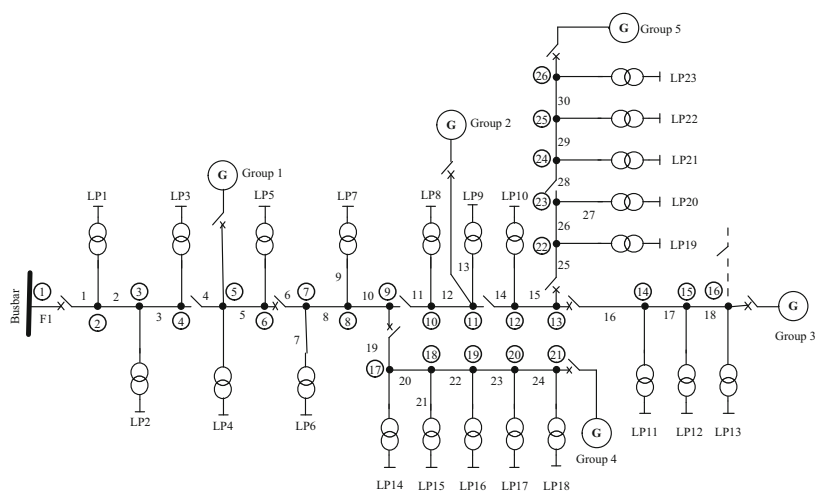

Fig. 6 Modified system under study

\section{Study case}

This paper uses the multi-branch feeders in the transformed IEEE RBTS Bus6 as examples, as shown in Fig. 6, including a segment bus (substation), 30 feeder segments, 26 nodes, 23 distribution transformers, 23 load points, 5 DGs, and several switches. Each DG includes several fans of the same type, a photovoltaic array and a battery, fan type is Enercon E33, the rated power of each WTG is 335 $\mathrm{kW}$, and the battery type is Hoppecke $24 \mathrm{OPzS} 3000$.

The length of each line segment and the peak of load point are the same as [47], the total load peak is 11.653 MW, and the time-varying load models are the same as [48]. The feeder failure rate is 0.065 times/year $\times \mathrm{km}$, the distribution transformer failure rate is 0.015 times/year, the average repair times are $5 \mathrm{~h}$ (repair rate is 0.2 times/h), distributed exponentially. Single wind turbine failure rate is 4.6 times/year, the repair rate is 58.4 times/year. The transfer rate of PV array is the same as the battery, $\lambda=$ 1.4, $\mu=58.4, \lambda_{d}=3.2, \mu_{d}=46.72, \lambda_{f}=11.68, \mu_{f}=0$, the unit is all times/year, the derating operation capacity is an half of the full state. Bus and switches are completely reliable, fault isolation and recovery time take constantly 1 $\mathrm{h}$, and the number of users for each load point is one.

\subsection{Low-carbon benefit of DG}

WTG PV and BESS are taken in each DG, the capacity of WTG is $1,005 \mathrm{~kW}$, the capacity of the PV is $1,005 \mathrm{~kW}$ and the capacity of the battery is $13,200 \mathrm{kWh}$, when calculated under different supply substation capacity constraints using this method, the system reliability indices are shown in Table 1 . We can see that, when the capacity of the supply substation is less than the total system load peak (11.653 MW), the generating indicators LOEE cease to be 0 , indicating that the system will face a shortage risk. With the decrease of the supply substation capacity, power generation and distribution reliability indices are increased, 
Table 1 Low-carbon benefit of DG

\begin{tabular}{llll}
\hline $\begin{array}{l}\text { Charge \& } \\
\text { Discharge strategy }\end{array}$ & $\begin{array}{l}\text { Substation } \\
\text { capacity (MW) }\end{array}$ & $\begin{array}{l}\text { LOEE } \\
(\mathrm{MW})\end{array}$ & $\begin{array}{l}\mathrm{CO}_{2} \text { emission } \\
\text { reduction }(\mathrm{t})\end{array}$ \\
\hline Load-following & 13 & 0 & 0 \\
& 11 & 3.4664 & 1.6244 \\
& 9 & 156.94 & 3.2488 \\
& 7 & 1174.6 & 4.8732 \\
& 5 & 3932.2 & 6.4976 \\
& 3 & 10653 & 8.122 \\
Cycle charge & 1 & 24362 & 9.7464 \\
& 13 & 0 & 0 \\
& 11 & 0.2931 & 1.6244 \\
& 9 & 14.24 & 3.2488 \\
& 7 & 260.84 & 4.8732 \\
& 5 & 2268.3 & 6.4976 \\
& 3 & 9145 & 8.122 \\
& 1 & 24161 & 9.7464 \\
\hline
\end{tabular}

especially the growth of power generation indices is more sensitive.

From Table 1 we can see that if we appropriately reduce the capacity of the supply substation, the system can still maintain a certain level of LOEE, whereas the $\mathrm{CO}_{2}$ emission reduction was increased linearly correlation with the reduction of supply capacity. Take cycle charging strategy for example, when supply substation capacity reduces to $9 \mathrm{MW}$, the system's total lack of power supply LOEE will be 14.24 MWh/year, which is still lower than 49.290 MWh/year which is the number before the DG accessed, and the $\mathrm{CO}_{2}$ emission reduction was $1.6244 \mathrm{t}$. This shows that after DG access to the distribution system, when there is no increase in the system load, the capacity of the supply substations may appropriately reduce. In other words, it reduces the $\mathrm{CO}_{2}$ emission. However, if the supply substation capacity reduce further, or only rely on the renewable DG to supply the load growth, the level of LOEE will increase greatly. For example, when the supply substation capacity is lowered to $7 \mathrm{MW}$, LOEE in cycle charging strategy will surge to 260.84 MWh/year.

\subsection{Impact on substation and DG capacity}

Table 2 shows the LOEE calculated with changing supply substation capacity and DG capacity in cycle charging strategy. The DGs access in different locations. Column in Table 2 stands for the supply distribution capacity while row stands for total DG capacity. Each " $\times 1$ " means that DG consists of WTG for $1,005 \mathrm{~kW}, \mathrm{PV}$ for $1,005 \mathrm{~kW}$ and BESS for 13,200 kWh. The capacity of DG in " $\times 2$ " is twice of that in " $\times 1$ ". The rest may be deduced by analogy.

From Table 2 we can see that in order to achieve a certain level of system reliability the capacity of supply substation and DG can be comprehensively selected. For example, when the requirement of LOEE is about 23 MWh/year, we can assume that the capacity of the supply substation is $11 \mathrm{MW}$ and the DG capacity is " $\times 1$ "; we can also assume that the supply substation capacity is $5 \mathrm{MW}$ and DG capacity is " $\times 6$ ". However, due to the volatility of the output of renewable DG, in order to maintain the LOEE level of the system, more DGs are needed to compensate for the reduced superior substation capacity. Compared with the former DGs, DGs in the latter became the main power supply in the system, meanwhile the supply substation capacity can decrease $6 \mathrm{MW}$, but the total capacity of the wind turbines and photovoltaic in the system will increase approximately $25 \mathrm{MW}$, while battery capacity will increase approximately $330 \mathrm{MWh}$. Therefore, when DG is the main power supply of the system, in order to ensure a certain degree of LOEE, total rated capacity of DG should be much higher than the system total load peak, and the cost is higher. According to the actual situation, we should reasonable optimize the capacity of supply substation and DG in order to meet the requirements of carbon emission reduction.

\subsection{System reliability assessment with DG integration}

Figure 7 shows the system average interruption frequency with the increase of DG capacity. The WTG capacity and the PV capacity units are $\mathrm{kW}$, the Section 4.2 means the BESS, its unit is kWh. Figure 8 shows the

Table 2 Impact on substation and DG capacity

\begin{tabular}{llllllll}
\hline Capacity & $\mathrm{CO}_{2}$ reduction $(\mathrm{t})$ & $\times 1$ & $\times 2$ & $\times 3$ & $\times 4$ & $\times 5$ & 16.701 \\
\hline 11 & 1.6244 & 25.097 & 18.295 & 17.402 & 17.03 & 16.911 & 17.371 \\
9 & 3.2488 & 39.113 & 23.467 & 19.442 & 18.114 & 16.876 \\
7 & 4.8732 & 286.591 & 96.966 & 66.349 & 42.081 & 23.958 & 17.283 \\
5 & 6.4976 & 2296.35 & 852.53 & 406.22 & 170.22 & 58.804 & 21.871 \\
\hline
\end{tabular}




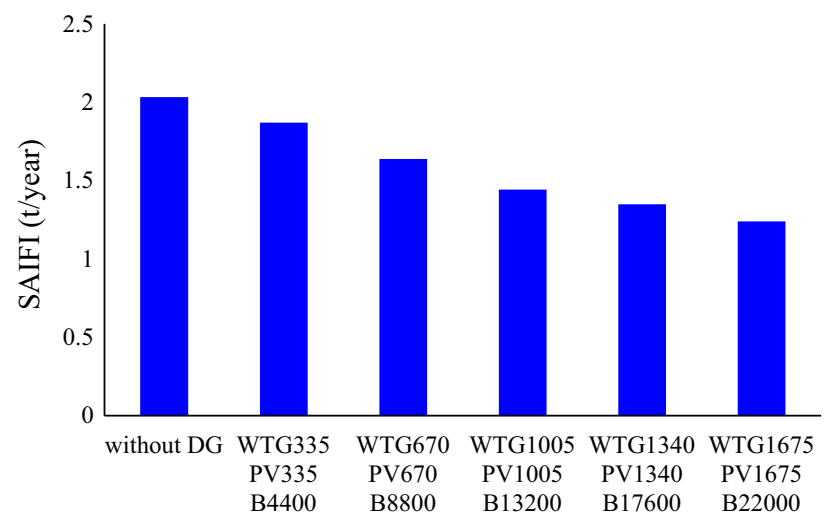

Fig. 7 System average interruption frequency with increase of DG capacity

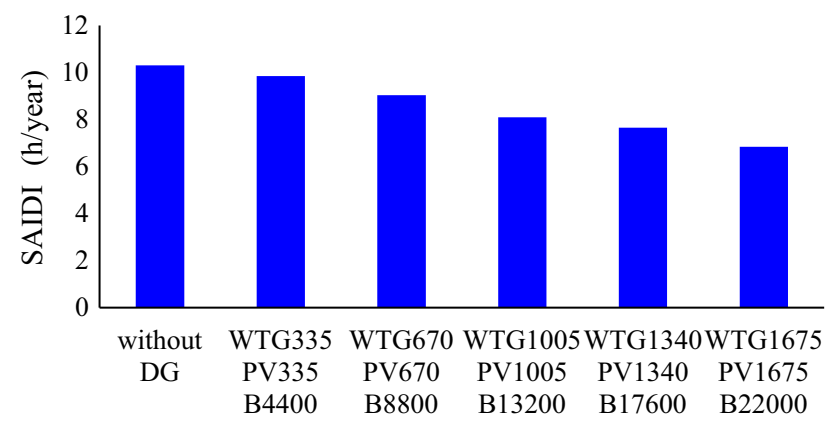

Fig. 8 System average interruption duration with increase of DG capacity

system average interruption duration with the increase of DG capacity.

System Average Interruption Frequency Index (SAIFI) and System Average Interruption Duration Index (SAIDI) are the most representative system reliability index. As can be seen from Fig. 7 and Fig. 8, DG can improve the reliability level of the system.

\section{Conclusion}

Low-carbon benefit assessment problem in 1 DG penetration active distribution system is treated by using Monte Carlo simulation method. Results indicate that the integration of DG can reduce the $\mathrm{CO}_{2}$ emission and increase the system reliability. The method can be applied to the planning and coordination of $\mathrm{CO}_{2}$ emission requirement of the power system.

Acknowledgements This work is supported by National Natural Science Foundation of China (No. 51477116), National Natural Science Foundation of China (No. 51261130473) and Special science and technology innovation project of Guangzhou Power Supply Company China Southern Power Grid (No. K-GZM2014-020).
Open Access This article is distributed under the terms of the Creative Commons Attribution License which permits any use, distribution, and reproduction in any medium, provided the original author(s) and the source are credited.

\section{References}

[1] Zhou TR, Chen QX, Zhu WT et al (2012) A comprehensive lowcarbon benefits assessment model for power systems. In: Proceedings of the 2012 IEEE international conference on power system technology (POWERCON'12), Auckland, 30 Oct-2 Nov 2012, 5 pp

[2] Lu SY, Wu YW, Lou SH et al (2014) A model for optimizing spinning reserve requirement of power system under low-carbon economy. IEEE Trans Sustain Energy 5(4):1048-1055

[3] Wu YW, Lou SH, Lu SY (2011) A model for power system interconnection planning under low-carbon economy with $\mathrm{CO}$ emission constraints. IEEE Trans Sustain Energy 2(3):205-214

[4] Hu XD, Zhou JH, Tan XD et al (2010) A low-carbon electricity model: Integrated resource strategic planning and its application. In: Proceedings of the 2010 IEEE Power and Energy Society general meeting, Minneapolis, 25-29 Jul 2010, 7 pp

[5] Wang XQ, Ding HW, Qiu MM et al (2011) A low-carbon production scheduling system considering renewable energy. In: Proceedings of the 2011 IEEE international conference on service operations, logistics, and informatics (SOLI'11), Beijing, 10-12 Jul 2011, pp 101-106

[6] Zhou TR, Kang CQ, Chen XY et al (2012) Evaluating lowcarbon effects of demand response from smart distribution grid. In: Proceedings of the 3rd IEEE PES international conference and exhibition on innovative smart grid technologies (ISGT Europe'12), Berlin, 14-17 Oct 2012, 6 pp

[7] Zhang QY, Wang J, Li JG et al (2012) Evaluation of the sequence of voltage levels based on low-carbon theory. In: Proceedings of the 2012 China international conference on electricity distribution (CICED'12), Shanghai, 10-14 Sept 2012, $4 \mathrm{pp}$

[8] Cui MY (2012) Low carbon dispatch of distribution network containing microgrid using chaotic ant swarm. In: Proceedings of the 2012 international conference on control engineering and communication technology (ICCECT'12), Shenyang, 7-9 Dec 2012, pp 818-821

[9] Ochoa LF, Mancarella P (2012) Low-carbon LV networks: challenges for planning and operation. In: Proceedings of the 2012 IEEE Power and Energy Society general meeting, San Diego, 22-26 Jul 2012, 2 pp

[10] Koutitas G (2010) Low carbon network planning. In: Proceedings of the 2010 European wireless conference (EW'10), Lucca, 12-15 Apr 2010, pp 411-417

[11] Ji Z, Kang CQ, Chen QX et al (2013) Low-carbon power system dispatch incorporating carbon capture power plants. IEEE Trans Power Syst 28(4):4615-4623

[12] Fang C, Chen LJ, Zhang Y et al (2014) Operation of low-carbon-emission microgrid considering wind power generation and compressed air energy storage. In: Proceedings of the 33rd Chinese control conference (CCC'14), Nanjing, 28-30 Jul 2014, pp 7472-7477

[13] Dong XW, El-Gorashi T, Elmirghani JMH (2011) Renewable energy for low carbon emission IP over WDM networks. In: Proceedings of the 15th international conference on optical network design and modeling (ONDM'11), Bologna, 8-10 Feb 2011, 6 pp 
[14] Huang XH, Zhang W, Ding H (2011) Research on Chinese lowcarbon economy mode and system. In: Proceedings of the 2011 international conference on electronics, communications and control (ICECC'11), Ningbo, 9-11 Sept 2011, pp 3881-3884

[15] Zhang XH, Jia RN, Tu GP (2012) Research on low-carbon energy policies selections based on SD modeling. In: Proceedings of the 2012 international symposium on management of technology (ISMOT'12), Hangzhou, 8-9 Nov 2012, pp 688-692

[16] Zhou ZY, Liu Y, Jin CP (2009) Study on construction of lowcarbon featured chlor-alkali industry bases energized by nongrid-connected wind power in offshore Jiangsu province. In: Proceedings of the world non-grid-connected wind power and energy conference (WNWEC'09), Nanjing, 24-26 Sept 2009, 4 $\mathrm{pp}$

[17] Cui MY, Ai X, Lei ZL (2010) Study on the low-carbon generation scheduling of distribution network containing microgrid. In: Proceedings of the 5th international conference on critical infrastructure (CRIS'10), Beijing, 20-22 Sept 2010, 4 pp

[18] Parkinson S, Wang D, Djilali N (2012) Toward low carbon energy systems: The convergence of wind power, demand response, and the electricity grid. In: Proceedings of the innovative smart grid technologies-Asia (ISGT Asia'12), Tianjin, 21-24 May 2012, 8 pp

[19] Capros P, Tasios N, Marinakis A (2012) Very high penetration of renewable energy sources to the European electricity system in the context of model-based analysis of an energy roadmap towards a low carbon EU economy by 2050. In: Proceedings of the 9th international conference on the European energy market (EEM'12), Florence, 10-12 May 2012, 8 pp

[20] Bie ZH, Li GF, Wang XF (2011) Review on reliability evaluation of new distribution system with micro-grid. Electr Power Autom Equip 31(1):1-6 (in Chinese)

[21] Liu CQ, Zhang Y (2007) Distribution network reliability considering distribution generation. Autom Electr Power Syst 31(22):46-49 (in Chinese)

[22] Qian KJ, Yuan Y, Zhou CK (2008) Study on impact of distributed generation on distribution system reliability. Power Syst Technol 32(11):74-78 (in Chinese)

[23] Zhu D, Broadwater RP, Tam KS et al (2006) Impact of DG placement on reliability and efficiency with time-varying loads. IEEE Trans Power Syst 21(1):419-427

[24] Bae IS, Kim JO (2007) Reliability evaluation of distributed generation based on operation mode. IEEE Trans Power Syst 22(2):785-790

[25] Billinton R, Li W (1993) A system state transition sampling method for composite system reliability evaluation. IEEE Trans Power Syst 8(3):761-767

[26] Atwa YM, EI-Saadany EF (2009) Reliability evaluation for distribution system with renewable distributed generation during Islanded mode of operation. IEEE Trans Power Syst 24(2):572-581

[27] Atwa YM, EI-Saadany EF, Guise AC (2010) Supply adequacy assessment of distribution system including wind-based DG during different modes of operation. IEEE Trans Power Syst 25(1):78-86

[28] Wang P, Billinton R (2001) Time-sequential simulation technique for rural distribution system reliability cost/worth evaluation including wind generation as alternative supply. IEE P-Gener Transm Distrib 148(4):355-360

[29] Wang P, Billinton R (2001) Reliability benefit analysis of adding WTG to a distribution system. IEEE Trans Energy Convers 16(2):134-139

[30] Park J, Liang W, Choi J et al (2009) A probabilistic reliability evaluation of a power system including solar/photovoltaic cell generator. In: Proceedings of the 2009 IEEE Power and Energy Society general meeting, Calgary, 26-30 Jul 2009, 6 pp
[31] Maliki G, Wang CS (2005) Reliability analysis on the integration of wind/PV hybrid distributed generation in distribution system. Autom Electr Power Syst 29(23):33-38 (in Chinese)

[32] Wang XD, Lin JK (2010) Reliability evaluation based on network simplification for the distribution system with distributed generation. Autom Electr Power Syst 34(4):38-43 (in Chinese)

[33] Ge SY, Wang HM, Wang YS et al (2012) Reliability evaluation of distribution system including distributed wind energy, solar energy and battery storage. Autom Electr Power Syst 36(5):16-23 (in Chinese)

[34] Savier JS, Das D (2007) Impacts of network reconfiguration on loss allocation of radial distribution systems. IEEE Trans Power Deliv 22(4):2473-2480

[35] Zhu D, Broadwater RP, Tam KS et al (2006) Impact of DG placement on reliability and efficiency with time-varying loads. IEEE Trans Power Syst 21(1):419-427

[36] Mitchell K, Nagrial M, Rizk J (2005) Simulation and optimization of renewable energy systems. Int J Electr Power Energy Syst 27(3):177-188

[37] Savier JS, Das D (2007) Impacts of network reconfiguration on loss allocation of radial distribution systems. IEEE Trans Power Deliv 22(4):2473-2480

[38] Fotuhi-Firuzabad M, Rajabi-Ghahnavie A (2005) An analytical method to consider DG impacts on distribution system reliability. In: Proceedings of the 2005 IEEE/PES transmission and distribution conference and exhibition: Asia and Pacific, Dalian, 14-18 Aug 2005, 6 pp

[39] Manwell JF, McGowan JG (1993) Lead acid battery storage model for hybrid energy systems. Solar Energy 50(5):399-405

[40] Billinton R, Wang P (1999) Teaching distribution system reliability evaluation using Monte Carlo simulation. IEEE Trans Power Syst 14(2):397-403

[41] Broadwater RP, Shaalan HE, Oka A et al (1994) Distribution system reliability and restoration analysis. Electr Power Syst Res 29(3):203-211

[42] Pregelj A, Begovic M, Rohatgi A (2006) Recloser allocation for improved reliability of DG-enhanced distribution network. IEEE Trans Power Syst 21(3):1442-1449

[43] Ge SY, Xu L, Liu H et al (2014) Reliability assessment of active distribution system using Monte Carlo simulation method. J Appl Math, 2014:1-10. Article ID 421347

[44] Lambert T, Gilman P, Lilienthal P (2006) Micropower system modeling with HOMER. In: Farret FA, Simoes MG (eds) Integration of alternative sources of energy. IEEE Press, Hoboken, pp 379-418

[45] Liu H, Han J, Ge SY et al (2014) Improved analytical method of power supply capability on distribution systems. Int J Electr Power Energy Syst 63:97-104

[46] Liu H, Guo YC, Ge SY et al (2014) Impact of DG configuration on maximum use of load supply capability in distribution power systems. J Appl Math, 2014:1-9. Article ID 136726

[47] Billinton R, Jonnavithula S (1996) A test system for teaching overall power system reliability assessment. IEEE Trans Power Syst 11(4):1670-1676

[48] Wang P, Billinton R (1999) Time sequential distribution system reliability worth analysis considering time varying load and cost models. IEEE Trans Power Deliv 14(3):1046-1051

Shaoyun GE received the Ph.D. degree in electrical engineering from Hong Kong Polytechnic University, 1998. Since 1988, he has been a researcher at the Urban Power System Planning, Optimal Operation and Control of Power System, and Smart Grid. He is a Professor at School of Electrical Engineering at Tianjin University, Tianjin, P. R. China. 
Li XU received the Undergraduate degree in 2010 and is currently pursuing the Ph.D. degree in the School of Electrical Engineering at Tianjin University, Tianjin, P. R. China. His research area is in Urban Power System Planning and Reliability Assessment of Distribution Power System.

Hong LIU the corresponding author, received the Ph.D. degree in Electrical Engineering from Tianjin University, 2009. Since 2009, he has been a researcher at the Urban Power System Planning, Smart
Grid and Electric Vehicle Charging Station. He is an Associate Professor at School of Electrical Engineering at Tianjin University, Tianjin, P. R. China.

Jian FANG has been a researcher at Distribution Power System Technology Supervisor and New Technology Promotion. He is an engineer at electric Power Research Institute, Guangzhou Power Supply Company, Guangzhou, P. R. China. 